\title{
The Moral Motivation in Treating Addictions as Basis of the Multidisciplinary Team Pedagogy
}

\section{DOI: http://doi.org/10.26758/9.1.5}

\author{
Constantin NECULA
}

"Andrei Şaguna" Faculty of Orthodox Theology, "Lucian Blaga" University of Sibiu

Address correspondence to: Constantin Necula, "Andrei Şaguna" Faculty of Orthodox Theology, "Lucian Blaga" University of Sibiu, 10, Victoriei Bd., Sibiu, 550024, Romania, Ph.: +40-(269)21-60-62; Fax: +40-(269)-21-78-87; E-mail: parintele_necula@yahoo.com

\begin{abstract}
Building the interventional diagnosis and support team seems to be the simplest method among the methods of the active intervention. However, choosing the intervention principles cannot be a morally indifferent process. This study is based on the analysis of the main references in the field, regarding the religious morals and the struggle against the isolation as form of noncombat in addiction, the moral sense of teamwork, and the prevention as related culture of intervention through the therapeutic team. Either we have to do with a Christian anthropology or with religious neutrality; either with a believer or nonbeliever, the intervention activity remains steady. It does not mean that it is neutral from the culture of intervention point of view. Thus, it becomes imperative to reconsider the moral motivation in treating the addiction, this being one of the keys of the forgiveness system, which foster the cultural resistance against this practice. Considering these, approaching the object of gnosiology and axiology could be the reason of a long-lasting solid research.
\end{abstract}

Keywords: moral landmarks, culture of intervention, cultural anthropology of addiction support, mixed-multidisciplinary team.

\section{Introduction}

Among the therapeutic preoccupations regarding the interventional professional group to support the persons with drugs or gambling addiction, the moral rebalance of the beneficiary is a priority. The main tendency identified in the last years in the diagnosis and therapy reveals an increasing need of 'forgiveness' whether social (from family or social group) or moral (related to God or any other immediate moral benchmarks). Considering Berger and Luckmann's (1969) analysis of reality as a picture of social construction, modern psychology has identified the broad parameters of a culture of psychosocial intervention, identified as a mechanism that produces common thinking and behavior to people belonging to a particular society. According to Taylor (1958), this conglomerate of behaviors and mentalities encompasses common knowledge, faith, art, morality and law, traditions, and any skill acquired in time by the person in the respective social slice (Abraham, 2013, pp. 275-290). He started from Robert Campbell Moberly's work (1845-1903), Atonement and Personality (Moberly, 1901), and highlights how the cultural thinking gathers in active cultural segments. The culture of addicted people, which mediates the reality between the addicted person's life and society as such, reveals extensive changes of the cultural anthropology related to addicted people.

Pollo (2007, p.267) offers us maybe one of the most articulate analysis, redefining the priorities of the cultural psychology of the substance abuse from different perspectives, including 
the psychotherapist's perspective, the social psychologist's perspective, and of any person involved in the process of recovering the addicted person. The motivation of psychotherapy, the culture dictated by the psychiatric experience of the person, constitute from his point of view, the psychotherapeutic language landmarks of the anthropological foundation of the therapy approach. The addicted person's relationship with the sacred is the key to questioning many aspects of psychotherapy or occupational therapy by which the person can be brought back in the positive social perimeter.

The research conducted in the last 10 years by the Blue Cross organization in Romania have demonstrated once more that establishing a religious reference point of therapy need is justified. Therapy should stay in close connection to religious dimension whether we are talking about the religious interpretation of addiction (Romania is still struggling with the mentality that the alcoholics and people addicted to drugs should not be helped, for they do it on their own free will) or of the religious scale of rethinking the motivation to be recovered from addiction.

\section{The religious morals and the struggle against the isolation as form of noncombat in addiction}

One of the first aspects identified in the cultural-anthropological profile of the addicted people I met, is related to a syndrome difficult to overcome, namely the syndrome of loneliness. Considering that this syndrome is connected to the syndrome of shame based sometimes on the religious censorship, it is obvious that the psychotherapeutic intervention implies a different approach.

The cooperation with the priests and the Church pastoral operators as well as with religious organizations (including Muslims or Mosaics organization) was initiated by the Blue Cross 20 years ago, when the central therapeutic team was reorganized. The reason of the cooperation was that including the religious aspect in intervention could reduce the social isolation for much more people. It is not about publicity or incitement to hunting the addicts, but a simple signaling formula that there is an alternative to isolation. The Blue Cross has initiated training courses for volunteers, for students of the theological faculty of Sibiu, has built mixed practice groups of theology and psychology students and psycho-pedagogues. Moreover, the organization cooperates with the universities of Sibiu, Târgu Mures, Cluj-Napoca and Braşov, offering practical opportunities for young students or graduates of medicine to know the cultural mechanism of the counseling and centered-person intervention in a world increasingly affected by the egocentric preoccupations in both American and European Western thinking.

Speaking about the frequency of isolated individuals cases, David D. Henderson highlighted the possible roots of isolation. According his opinion, the feeling of isolation was foster by the four psychologists' approach of counseling. Influenced by the Second World War optimism, the four psychologists (Abraham Maslow, Carl Rogers, Erich Fromm and Rollo May) developed a new approach of counseling. This therapy style focused on building high selfesteem of the counseled person was based on four supreme values:

- $\quad$ Self-understanding: establishing a connection with what I feel

- $\quad$ Self-acceptance: a positive outlook on myself, no matter what I say or do;

- $\quad$ Self-expression: be myself - define myself - without taking into account the others;

- $\quad$ Self-satisfaction: fulfilling my needs of being happy.

The central theme of the fours psychologists' thinking was the belief that we as humans are essentially good, that we are equipped with everything we need to grow and be healed. Therefore, Rogers developed a counseling style in which there was no confrontation, and nothing was criticized. He called it 'reflective listening', which implied summarizing what the speaker said and embracing his/her perspective without necessarily agreeing with it ("this is what I think you said"). Moreover, this kind of doing therapy fostered the client's feeling of fully 
acceptance "regardless of his/her feelings... no matter how his/her speech is... exactly as he is" (Rogers, 1961, p. 130). In other words, "I am special, wonderful, and unique, worthy to be respected by others by the mere fact that I am myself". Any standards of evaluating character, integrity or responsibility are removed. The name of the 'game' is acceptance (Henderson, 2014, p. 304)

Henderson identifies a series of shortcomings of the four psychologists' theory. For instance, Maslow's ideas were quickly assumed by the dominant cultural stream directed to selfconcern, which became rapidly the way a nation defined its problems in selfish individualistic terms: "it matters our needs, our rights, and not our responsibilities at all".

The most relevant movement in therapy is that of the therapeutic culture of good mood (Wuthnow, March, 1995, p. 41, cited by Henderson, 2014), whose foundations are still alive in the culture of academics and which does not agree with the practice of intervention / counseling. The theory consists of the opinion that the individual is defined only by his needs and motivated only by satisfying them.

Henderson however, understands that these principles have weakened the moral order, whether or not Christian, related to the addicted person. He identifies some changing in focus:

1. from God to humanity;

2. from group to individual;

3. from responsibilities to rights ;

4. from the other to self-perspective;

5. from serving to self-expression;

6. from blessings to the needs (Henderson, 2014, p. 120).

All these aspects have led to a new individualism, which isolates the human being from itself, from the neighbour and from the moral source of its life, regardless how it is called. The solitary police officer's syndrome is thus, expressed in some cultural behaviors that can be identified in most cases of addicted people and occurs in the first phase of case analysis: 'I do not need anyone's company'; 'safety in the virtual community'; 'a man's house is his bunker'; 'Mind your own business'; 'today here, tomorrow far away'; 'I know what I want and when I want'; 'I'm not my brother's keeper'. Henderson's conclusion is simple (Henderson, 2014, pp. 120-126, with a rich bibliography and a systematic presentation of every syndrome) and based on some researches on individualism: we have passed from self-made man to self made by man (Leinberger and Tucker, 1991).

This excursus on 'social dogmatics', as we dare to call it, preceded the conclusion of some particular observations regarding the addicted people in Romania treated and observed by us in their therapeutic evolution during 1998 and 2018.

In the beginning, the Blue Cross dealt with people addicted to alcohol. Since 2005, the number of persons addicted to drugs and gambling has significantly increased. In the last years there were much more requests for drugs and gambling addiction treatment assistance, as if the alcohol addiction is no more such a problem.

We do not have a systematic analysis of gambling addiction, but we can evaluate its social impact based on the data emphasized in the recent book of Armando Angelucci and Claudia Bartalucci (Angelucci and Bartalucci, 2017, p. 160). They describe the situation in the year 2017 in Italy, asserting that $54 \%$ of Italians practiced gambling at least once in a year; 2,296,000 were 'problematic' gamblers and 1,329,000 were 'pathological' gamblers.

The authors consider these gaming extremely dangerous, real hazards, for they have neither rules nor physical or psychical boundaries, and compromise the human relationships and the daily reality. The lives of the gamblers (less of the producers, but more of the consumers and of their families) are undermined. 
Among the solutions to escape from isolation and despair, the two authors mention the individual, couple and family counseling, and building a person-centered assistance support related to his/her immediate needs.

\section{The moral sense of teamwork}

There should be taken into consideration the difficulty of the psychotherapist's intervention and the need to set up a psychotherapeutic team. In the context in which addictions changed their contents and their pathological expression, notes on the emergence of depressions, tendencies and acts of suicide, anorexia or bulimia as a multiple syndrome linked to addiction and end-stage diseases and insists on the need to develop research in order to deepen this relevance (De Stefano, 2017, p. 112), the former Blue Cross team of physician, psychologist, and psychotherapist, was joined in time by clinical psychologist, occupational therapist and religious counselor (initially a layman and today a priest). Why the need to restore the religious counseling, which in the beginning of the International Blue Cross was in fact fundamental to therapy? Evaluating more than 100 cases, we observed that the addicted person's isolation is caused by the exclusion from his/her family and the social ethos. There is no addiction without a social visibility, even if we speak about the porn addiction, which in the first phase does not affect the public image of the person. Hence, addiction has great impact in public due to the addicted person's smell, attitudes, lack of focus and professional concentration, destabilization of collectives through violence, domestic violence. Unbelievable as it may sound, persons addicted to gambling or even games of chance, influence through absenteeism, increased irritability, and violent language their working teams. In most of the analyzed cases either in personal or in a team consultation, we observed that the target group comprised especially young people, who were still looking for the meaning of life, which sometimes made them look for soft financial solutions to present financial problems.

When gambling exceeds pleasure and riches the level of the material gain not only in the case of addictions, we have to go further with the analysis, considering the reality of addiction. That means we have to include in our analysis the reality of the human weaken will put in the service of a construction that destabilizes the balance of the beneficiary. We are overtaken by technology and fall from use to abuse and then, to addiction. The role of the relationships in the mixed or multiple-mixed support and diagnosis team are developed in relation to the complexity of intervention. All addictions have the same pattern. However, their pathology increased and new forms emerged as Internet Addiction Disorder (IAD), Cybersex Addiction, Information Overloading Addiction, On-line Gambling, Cyberchondria. (Portelli and Papantuono, 2017, p. 189). Therefore, the culture of teamwork is becoming more and more important, based on a common training but with particularities for all those who are responsible for the effort of therapy. From therapeutic practice results a systemic reality. Analyzing the first men's and women's interviews (pre-hospitalized at the Sura Mica or Şelimbăr psychotherapy centers), the dialogue with a great number of addicted subjects (mostly multiple addicted) remind us of the words of the famous drunkard (the character of the novel Little Prince written by Antoine de Saint-Exupéry): "I am drinking to forget that I am ashamed of drinking". Moreover, the analyses make clear a primary spiritual confusion of the addicted individual, caused by the fact that they are rejected both by their families and by the group pressure. Moreover, most of them were suffering of depression at the time of admission in the centers (Borowiak, 2007, p. 191).

In other words, they were isolated by themselves. Analyzing the stages of addiction recovery program, we noticed that the intervention of the team of physician-psychologistpsychotherapist was improved by introducing the priest or the catechist in the therapeutic process. Thus, the therapy includes today the prayer group, reading Scripture, both formal and 
informal religious education (catechesis), spiritual evaluation of someone's life project. In the latest psycho-pedagogical researches on alcohol consumption, for example, the specialists have noticed a worrying increase in family dissolution. They speak especially about Marital Dissolution and Marital Interaction Processes (Cranford and Fairbairn, 2018).

Considering all these, we assert that the first evaluation carefully conducted by physician and psychologist is extremely important, but not enough (Lambron, 2017, p. 368). In the training programs of medical personnel it is necessary to introduce a discipline that will complement its knowledge in order to facilitate the integrated diagnosis and recovery process of the drug-addicted persons (Baciu, 2017a). The rebalancing effort cannot ignore the marital counseling specialist, who rebuilds in time the functional parameters of marriage in the mental mechanism and the culture of resistance to the pressure of the problem arising in the (oftenimaginative) context of marriage. In very many cases, the priest can help to rebalance the antidivorce resistance or to heal the syndrome of pastoral violence. The priest becomes also the mediator of the patient's dialogue with himself/herself, with God and the fellows, because much of the success of a therapy comes from the creation of an escape space, a kind of Zoar city, in which the therapy is positively influenced by the presence of family's forgiveness. Of course, things happen different in the cases of alcoholic couples or even alcohol-consuming families, which unfortunately have increased.

\section{Prevention as related culture of intervention through the therapeutic team}

Another aspect of building a mixed performing team is prevention.

Insisting on educating mature people's responsibility regarding alcohol consumption and educating the young people to non-consumption attitude, encouraging organizations that promote it a healthy life style among teenagers, in order to diminish the negative effects of alcohol, needs to be encouraged (Baciu, 2014). It is an extraordinary proposal based on the levels of prevention defined by the World Health Organization as primary, secondary and tertiary prevention. Primary prevention aimed at reducing the incidence and disappearance of new drinking problems. The secondary prevention focuses on reducing the frequency of cases that already exist and the tertiary prevention tries to reduce the severity of existing complications, monitoring addicted people or their relatives.

In each of these phases, there is a need to build mixed teams in which, for example, the priest can identify in the school or at the addicted person's workplace those people who can become the netting knots of a safety net in order to optimize the addicted person's therapy. The same core team could effectively struggle to limit of assimilation of the social advertising related to the addiction process; could develop prevention projects within the schools by developing the information system regarding addiction topics, and proposing responsible attitudes towards the anti-abuse education. Moreover, the core team could propose a coherent alternative related to the culture of the risk of addiction to the culture of entertainment, and develops the channels of true communication among teachers, students and family in the family environment (Kuntz, 2016, p. 381; Lindenmeyer, 2016, p. 126). Finally, an educational platform should be developed to reduce the impact of addiction on the young population, and foster the moral motivation of the youth. Drug use cannot be stopped but it can be reduced through a better education and process of informing the entire society and addicts have to be perceived as people who have a serious problem, with chances of recovery (Baciu, 2017b, p. 91).

To prevent the family alcohol addiction, we have to build relational bridges based on sincerity and mutual trust. Saving an addicted person from isolation, regardless his/her age, should start with creating a safety space that enables the team to attentively observe the recovery process and to professionally reconfigure it. In the case of adolescents, for example, it becomes important for them to learn how to take emotional distance to avoid conflict, how to understand 
the mechanism of violence and the process of passing from aggression to mature, responsible behavior (Valsecchi, 2010, p. 158).

\section{Conclusions}

To conclude, it is obvious in the practice that in the case of the alcohol addicted person, the intervention team must comprise first the individual in crisis. He/She can open channels of communication or close, sometimes definitively, the horizon of any cooperation. However, this should not affect the family, the experts, the support team or the people usually present in his/her daily life. Therefore, reconsidering the moral motivation in treating the addiction becomes imperative. It is the key of the forgiveness system, which foster the cultural resistance against addiction. The success of the therapy is based on the person's free will that characterizes the true man's life without addiction or death.

\section{Bibliography}

1. Abraham, W.J., 2013. Analytic Philosophers of Religion, in the volume The Spiritual Senses. Perceiving God in Western Christianity, edited by Paul L. Gavrilyuc and S. Coakley, London: Cambridge University Press, pp. 275-290.

2. Angelucci, A. and Bartalucci, C., 2017. Non e solo un gioco - Superare la dipendenza dal giocco dezzardo (coll. Progetto famiglia), Alba: San Paolo Edizioni, p. 160.

3. Baciu, A., 2017a. Persoanele toxico dependente - o provocare pentru personalul medical din România?. În Antropologie şi educație, coord.: Kozma, A., Glavce, C., Bălăceanu-Stolnici, C. București: Ed. Academiei Române, 10, pp. 118-124.

4. Baciu, A., 2014. Anthropo-medical correlations regarding the alcohol consumption among teenagers. Proceedings of the Romanian Academy. Series B. București: Edit. Academiei Române, 16(3): 143-154.

5. Baciu, A.B., 2017b. Drug Use - A Medical, Anthropological and Psychosocial Phenomenon. Aachen: Edit. Shaker Verlag, p. 91.

6. Berger, P.L. and Luckmann, T., 1969. La realta come construzione sociale. Bologna: Il Mulino.

7. Borowiak, S., 2007. ALK-Fast ein medizinisches Sachbuch. Munchen: Wilhelm Heyne Verlag, p. 191.

8. Cranford, J.A. and Fairbairn, C.E., 2018. Social Psychology of Alcohol Involvement, Marital Dissolution, and Marital Interaction Processes across Multiple Timescales. In the volume Alcohol Use Disorders. A Developmental Science Approach to Etiology (edited by Hiram E. Fitzgerald and Leon I. Puttler). Oxford University Press, pp. 324- 337.

9. De Stefano, D., 2017. Chi segne me avra la luce della vita-La questione del senso, la domanda nella sofferenza e il problema delle dipendenze patologiche (coll. Vivae Voces). Rome: Lateran University Press, p. 112.

10. Henderson, D.D., 2014. Cultură în schimbare. Comunicând adevărul divin lumii contemporane. Oradea: Life Publishers, p. 304.

11. Kuntz, H., 2016. Drogen\&Sucht. Was sie Wissen Müssen. Weinheim: Beltz Verlag, p. 381.

12. Lambron, U., 2017. Familienkrankheit Alkolismus. In Sog der Abhangigkeit. Hamburg, p. 368, p. 368.

13. Leinberger, P. and Tucker, B., 1991. The New Individualists. New York: Harper Collins.

14. Lindenmeyer, J., 2016. Alkoholabhangigkeit. Gottingen: Hogrefe Verlag, p. 126.

15. Moberly, R. C., 1901. Atonement and Personality. London: John Murray.

16. Polo, M., 2007. Il crollo della mente sacra. Verso una psicologia culturale delle tossico dipendenze. Roma: Aracne Editrice, p. 267. 
17. Portelli, C. and Papantuono, M., 2017. Le nuove dependenze. Riconoscerle, capire e superarle. Alba: San Paolo, p. 189.

18. Rogers, C., 1961. On Becoming a Person. Boston: Houghton Mifflin.

19. Taylor, E.B., 1958. The Origins of Culture. New York: Harper Torchbooks.

20. Valsecchi, E., 2010. Adolescenti in bottiglia. Ragazzi e alcol: che are?. Milano: Ancora, p. 158.

21. Wuthnow, R., 1995. The Scandal of Evangelical Mind, First Things, cited by Henderson, D.D., 2014. Cultură în schimbare. Comunicând adevărul divin lumii contemporane. Oradea: Life Publishers, p. 4. 